\title{
ANALISIS MOTIVASI BELAJAR SISWA KELAS VII SMP N 11 PEKALONGAN MENGGUNAKAN APLIKASI MOBILE LEARNING BERBASIS ANDROID SEBAGAI MEDIA PEMBELAJARAN JARAK JAUH \\ ${ }^{1)}$ Muhammad Choirul Kamal, ${ }^{2}$ Evi Sugiana Purnamasari \\ 1) SMPN 11 Pekalongan, ${ }^{2}$ 'SMPN 6 Pekalongan \\ ${ }^{1)}$ muhammadchoirulkamal@gmail.com ${ }^{2)}$ ephi27@gmail.com
}

Received:
04/06/2021
Accepted:
03/07/2021
Published:
04/07/2021

\begin{abstract}
This paper aims to know the learning motivation of android-based mobile learning application usage as a medium of long distance learning (PJJ) for grade VII students SMPN 11 Pekalongan. This paper is implemented at SMPN 11 Pekalongan in grade VII E, VII F, and VII G students through whatsapp and google classroom. The method used in this paper is qualitative method which is descriptive analysis. The data collection is used open and closed questionnaires and interviews to students of grade VII E, VII, F, VII G SMPN 11 Pekalongan. Based on the questionnaires and the interviews conducted by researcher, it shows $86.5 \%$ of students have high learning motivation in PJJ, and the usage of android-based mobile learning applications also can be an alternative for students to study and to understand the learning materials well.
\end{abstract}

Keywords: Mobile Learning, Distance Learning, Motivation Learning

\begin{abstract}
Abstrak
Penelitian ini bertujuan untuk mengetahui motivasi belajar menggunakan aplikasi mobile learning berbasis android sebagai media pembelajaran jarak jauh siswa kelas VII SMPN 11 Pekalongan. Penelitian ini dilaksanakan di SMPN 11 Pekalongan pada siswa kelas VII E, VII F, dan VII G melalui whatsapp dan google classroom. Metode yang digunakan dalam karya tulis ini adalah metode kualitatif dengan analisis desksriptif. Di mana dalam pengumpulan datanya digunakan angket terbuka dan tertutup serta wawancara kepada siswa kelas VII E, VII F, dan VII G SMPN 11 Pekalongan. Berdasarkan hasil angket dan wawancara yang telah dilakukan oleh peneliti bahwa dengan penggunaan aplikasi mobile learning berbasis android sebagai media PJJ siswa kelas VII SMPN 11 Pekalongan menunjukkan 86,5\% siswa memiliki motivasi belajar yang tinggi dalam PJJ, dan dengan penggunaan aplikasi mobile learning berbasis android juga dapat menjadi alternatif untuk siswa dapat belajar dan memahami materi pembelajaran dengan baik.
\end{abstract}

Kata Kunci: Mobile Learning, Pembelajaran Jarak Jauh, Motivasi Belajar

\section{Pendahuluan}

Sejak bulan Maret 2020 Indonesia terkena dampak pandemi Covid-19 hingga saat ini, segala aspek dalam kehidupan menjadi terhambat mulai dari kesehatan, ekonomi, dan pendidikan. Pemerintah Indonesia menerapkan kebijakan social distancing untuk mencegah penyebaran Covid-19 termasuk dalam aktivitas pendidikan. Pemerintah melalui Kementrian Pendidikan dan Kebudayaan menerapkan kebijakan Pembelajaran Jarak Jauh (PJJ) untuk mencegah timbulnya klaster baru di sekolahsekolah. 

Vol. 9 No. 2 Bulan Juli hal. $285-292$

Mendikbud melalui surat edaran nomor 4 tahun 2020 menginstruksikan kepada seluruh civitas pendidikan untuk melaksanakan belajar dari rumah melalui pembelajaran jarak jauh. Salah satu poin dalam surat edaran tersebut adalah guru diminta memberikan variasi aktivitas dan tugas pembelajaran belajar dari rumah dengan tetap mempertimbangkan kesenjangan akses atau fasilitas belajar yang dimiliki masingmasing siswa. Dengan kata lain guru tetap melibatkan siswa untuk terus belajar meskipun kegiatan sekolah normal terganggu.

Di sisi yang lain, berdasarkan survei Komisi Perlindungan Anak Indonesia (KPAI) terhadap 1.700 siswa berbagai jenjang pendidikan pada 13 - 20 April 2020, sekitar 76,7 persen di antaranya mengaku tidak senang mengikuti pembelajaran jarak jauh (PJJ). Hanya 23,3 persen responden yang menganggap PJJ mengesankan. Pun demikian dengan peserta didik SMP Negeri 11 Pekalongan, berdasarkan angket internal yang dilaksanakan 15 - 22 Oktober 2020 lebih dari 60 persen peserta didik mengalami kejenuhan dalam menjalankan pembelajaran jarak jauh.

Dalam angket internal SMP Negeri 11 Pekalongan tentang PJJ juga menyinggung tentang frekuensi peserta didik bermain game dalam sehari, hasilnya lebih dari $63 \%$ peserta didik bermain game lebih dari 1 jam dalam sehari. Hal ini yang mendorong penulis untuk mentransformasikan materi pelajaran dalam pembelajaran jarak jauh menjadi tampilan yang lebih menarik seperti sebuah game.

Smart Apps Creator merupakan aplikasi untuk membuat aplikasi mobile android dan iOS tanpa kode pemrograman, serta dapat menghasilkan format HTML5 dan .exe. sehingga aplikasi tersebut lebih mudah digunakan oleh para guru membuat kontenkonten mobile learning untuk peserta didik. Peserta didik juga lebih mudah memasang aplikasi pada gadget karena aplikasi ini tidak memiliki syarat khusus, selain itu tampilan mobile learning yang dibuat menggunakan Smart Apps Creator sangat menarik layaknya tampilan game.

Melalui aplikasi mobile learning berbasis android ini diharapkan mampu memberikan pengalaman belajar baru bagi peserta didik dan memberikan motivasi serta semangat belajar bagi mereka. Aplikasi mobile learning berbasis android ini merupakan penunjang pembelajaran jarak jauh yang juga berfungsi sebagai alternatif mengurangi penggunaan game yang kurang bermanfaat bagi anak. Hal ini dimaksudkan agar peserta didik lebih gemar memainkan aplikasi mobile learning berbasis android untuk belajar dan "bermain". 
Untuk memecahkan permasalahan diatas, penulis menggunakan dan mengembangkan aplikasi mobile learning berbasis android dalam pembelajaran secara optimal, maka dalam penulisan karya ini berjudul "Analisis Motivasi Belajar Siswa Kelas VII SMP N 11 Pekalongan Menggunakan Aplikasi Mobile Learning Berbasis Android sebagai Media Pembelajaran Jarak Jauh”.

Adapun tujuan dilakukannya penelitian ini adalah untuk mengetahui motivasi belajar siswa menggunakan aplikasi mobile learning berbasis android dalam pembelajaran jarak jauh peserta didik SMP Negeri 11 Pekalongan. Sedangkan manfaat penelitian ini sebagai berikut

a. Bagi peserta didik: aplikasi mobile learning berbasis android menjadi salah satu alternatif media pembelajaran jarak jauh yang menarik dan menumbuhkan motivasi belajar bagi peserta didik SMP Negeri 11 Pekalongan;

b. Bagi guru: menjadi pemicu bagi guru SMP Negeri 11 Pekalongan untuk berkreasi dan berinovasi membuat berbagai macam alternatif model pembelajaran jarak jauh.

\section{Metode Penelitian}

Penelitian ini bertujuan untuk mengetahui motivasi belajar siswa menggunakan aplikasi mobile learning berbasis android dalam pembelajaran jarak jauh peserta didik SMP Negeri 11 Pekalongan. Penelitian ini menggunakan pendekatan kualitatif dengan analisis deskriptif, di mana penelitian tersebut merupakan penelitian yang menghasilkan data deskriptif berupa kata-kata secara tertulis maupun secara lisan dari orang-orang dan perilaku yang diamati. Penelitian ini dilakukan di SMP Negeri 11 Pekalongan pada bulan Oktober tahun pelajaran 2020/2021 di kelas VII E, VII F, dan VII G. di mana dalam pengambilan data, peneliti menggunakan kombinasi bentuk angket, yaitu terbuka dan tertutup. "Uno (2016) menguraikan indikatornya sebagai berikut

a. Adanya hasrat dan keinginan berhasil;

b. Adanya dorongan dan kebutuhan dalam belajar;

c. Adanya harapan dan cita-cita masa depan;

d. Adanya penghargaan dalam belajar;

e. Adanya kegiatan yang menarik dalam belajar;

f. Adanya lingkungan belajar yang kondusif sehingga memungkinkan seseorang siswa dapat belajar lebih baik." 
Kemudian hasil dari jawaban siswa kelas VII E, VII F, dan VII G akan dianalisis berdasarkan indikator tersebut.

\section{Hasil dan Pembahasan}

\subsection{Alasan Strategi Pemecahan Masalah Yang Dipilih}

Alasan pemilihan strategi pemecahan masalah yang dipilih pada pembelajaran jarak jauh mata pelajaran matematika kelas VII di SMP Negeri 11 Pekalongan dengan penggunaan aplikasi mobile learning berbasis android adalah agar peserta didik termotivasi untuk mengikuti pembelajaran jauh mata pelajaran matematika. Dengan penggunaan aplikasi mobile learning berbasis android diharapkan dapat menurunkan tingkat kejenuhan peserta didik dalam mengikuti pembelajaran jarak jauh yang selama ini dilaksanakan.

Melalui aplikasi mobile learning berbasis android ini diharapkan mampu memberikan pengalaman belajar baru bagi peserta didik. Aplikasi mobile learning berbasis android ini merupakan penunjang pembelajaran jarak jauh yang juga berfungsi sebagai alternatif mengurangi penggunaan game yang kurang bermanfaat bagi anak. Hal ini dimaksudkan agar peserta didik lebih gemar memainkan aplikasi mobile learning berbasis android untuk belajar dan "bermain".

Fokus pembelajaran ini adalah dengan penggunaan aplikasi mobile learning berbasis android, dimana peserta didik melaksanakan pembelajaran jarak jauh dan mengerjakan penugasan dengan aplikasi mobile learning sebagai penunjang untuk belajar. Hasil dari penugasan ini kemudian didiskusikan kembali di grup belajar yang telah dibuat oleh guru.

\subsection{Tahapan Operasional Pelaksanaan Pemecahan Masalah}

Tahapan operasional pelaksanaan pembelajaran dengan penggunaan aplikasi mobile learning berbasis android terdiri atas bebrapa langkah berikut

a. Pembuatan aplikasi mobile learning berbasis android

Pembuatan aplikasi mobile learning berbasis android dibuat oleh penulis dengan menggunakan software Smart Apps Creator. Dalam aplikasi ini terdiri dari beberapa fitur yang berbentuk tombol: kompetensi dasar, materi, kuis, dan informasi mengenai pembuat aplikasi (developer aplikasi). Berikut tampilan layar dari fitur-fitur yang ada dalam aplikasi mobile learning berbasis android 
1. Tampilan pembuka

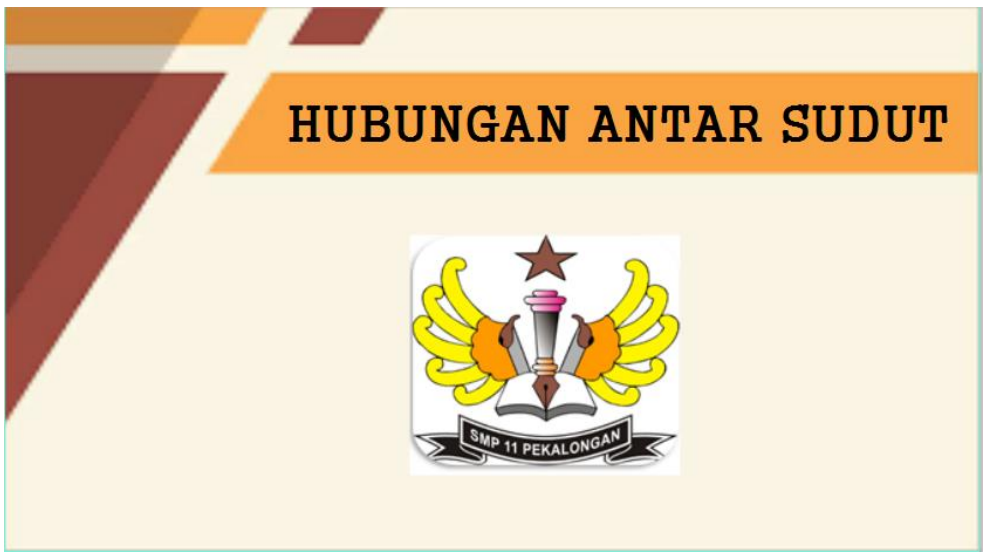

Gambar 1. Tampilan pembuka

2. Tampilan halaman utama (home)

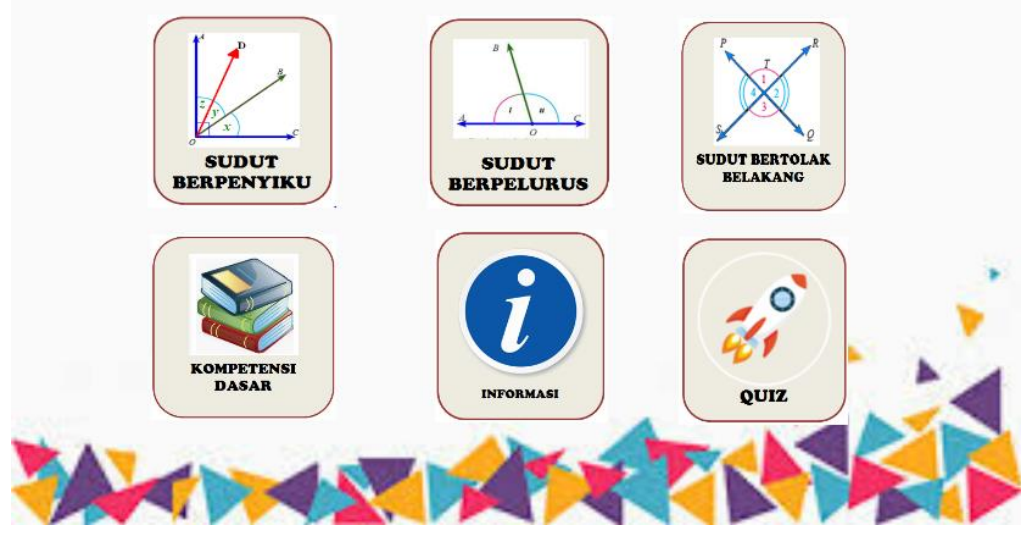

Gambar 2. Tampilan halaman utama

3. Tampilan kompetensi dasar

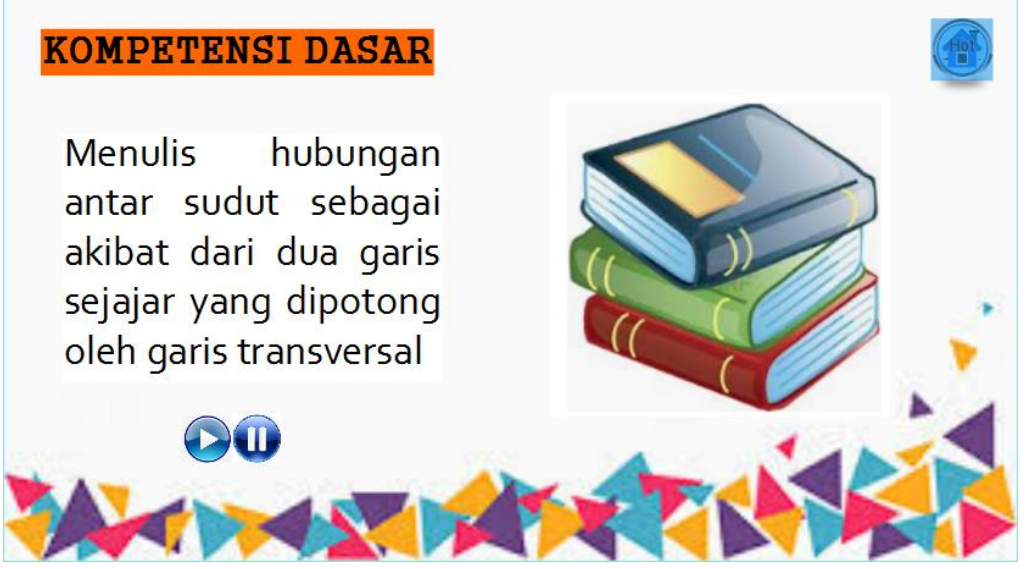

Gambar 3. Tampilan kompetensi dasar

4. Tampilan materi 


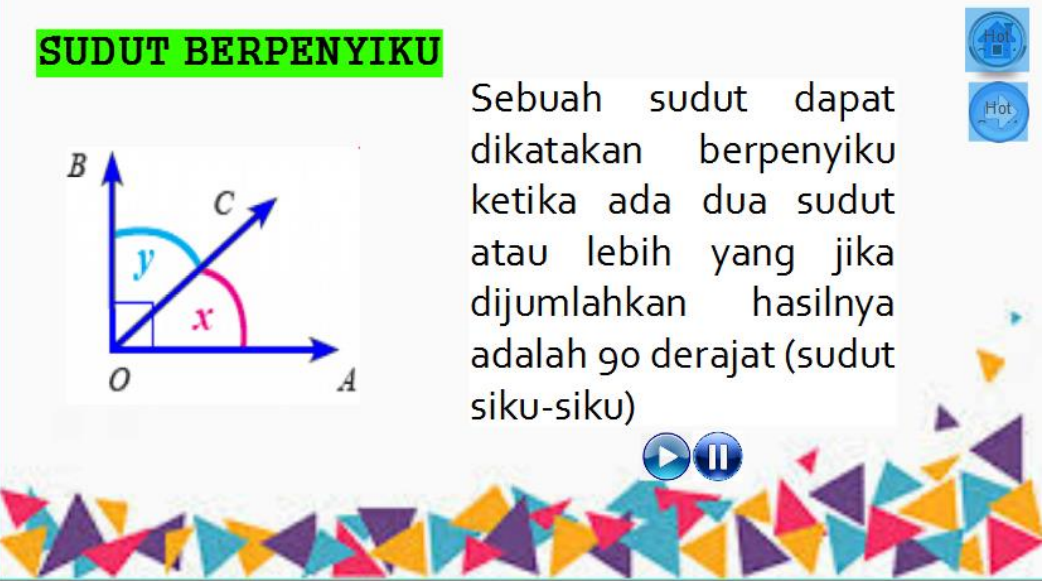

Gambar 4. Tampilan materi

5. Tampilan kuis

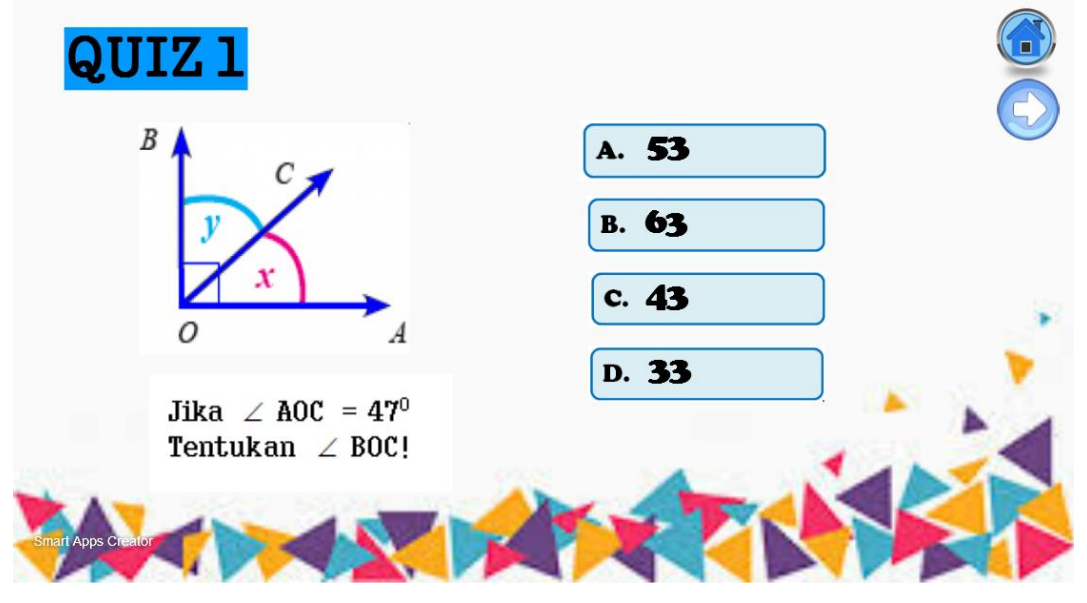

Gambar 5. Tampilan kuis

6. Tampilan informasi

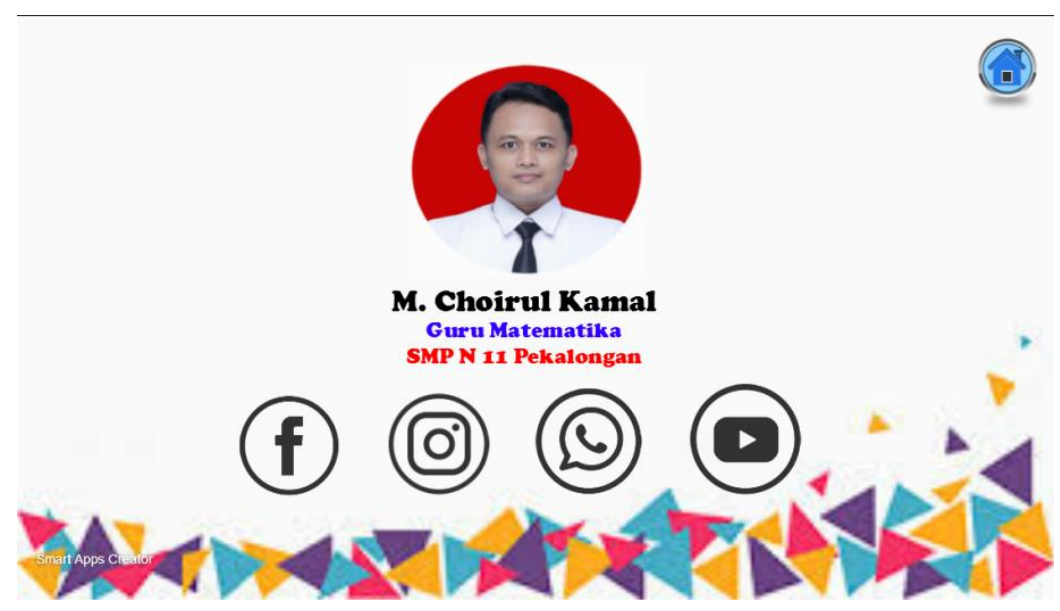

Gambar 6. Tampilan informasi

b. Distribusi aplikasi mobile learning berbasis android

Distribusi aplikasi mobile learning berbasis android kepada peserta didik melalui whatsapp group maupun google classroom yang telah dibuat oleh guru. 
Kamal dan Purnamasari, Penggunaan Aplikasi Mobile Learning ...

Guru mengirimkan link untuk diunduh oleh peserta didik, kemudian di-install pada telepon seluler android masing-masing. Aplikasi mobile learning berbasis android juga dapat di-install pada laptop maupun komputer dengan bantuan emulator software (misalnya software Nox-Emulator). Aplikasi mobile learning berbasis android dapat diunduh melalui link sebagai berikut: https://drive.google.com/file/d/1XNVigV-

THBuJrdNvmeJ0207rITONH D7/view?usp=sharing

\subsection{Hasil yang Dicapai}

Hasil yang dicapai dari penggunaan aplikasi mobile learning berbasis android pada peserta didik kela VII SMP Negeri 11 Pekalongan akan ditampilkan dalam tabel sebagai berikut

Tabel 1. Hasil penggunaan aplikasi mobile learning berbasis android

\begin{tabular}{lccc}
\hline \multicolumn{1}{c}{ Indikator } & Target & \multicolumn{2}{c}{ Ketercapaian } \\
& & Observasi & Angket \\
\hline Adanya hasrat dan keinginan berhasil & $75 \%$ & $81 \%$ & $83 \%$ \\
Adanya dorongan dan kebutuhan dalam belajar & $75 \%$ & $82 \%$ & $87 \%$ \\
Adanya harapan dan cita-cita masa depan & $75 \%$ & $85 \%$ & $86 \%$ \\
Adanya penghargaan dalam belajar & $75 \%$ & $83 \%$ & $85 \%$ \\
Adanya kegiatan yang menarik dalam belajar & $75 \%$ & $91 \%$ & $88 \%$ \\
Adanya lingkungan belajar yang kondusif & $75 \%$ & $93 \%$ & $90 \%$ \\
\hline
\end{tabular}

(Sumber: Data primer yang diolah, 2020)

Dari data tersebut dapat dilihat bahwa capaian pada tiap indikator telah melampaui target yang ditentukan yakni $75 \%$. Peserta didik tampak sangat antusias dengan aplikasi mobile learning berbasis android, karena media ini merupakan hal baru di SMP Negeri 11 Pekalongan. Selain itu tampilan dari aplikasi mobile learning berbasis android sangat menarik seperti game yang biasa mereka mainkan di ponsel. Dapat disimpulkan bahwa penggunaan aplikasi mobile learning berbasis android sebagai media pembelajaran jarak jauh peserta didik kelas VII SMP Negeri 11 Pekalongan sangat efektif dan dapat menumbuhkan motivasi belajar peserta didik kelas VII SMP Negeri 11 Pekalongan. Rata-rata ketercapaian indikator melalui observasi sebesar $85,8 \%$ dan ketercapaian indikator melalui angket adalah $86,5 \%$.

\section{Kesimpulan dan Saran}


Berdasarkan hasil penelitian yang telah dilakukan oleh peneliti bahwa penggunaan aplikasi mobile learning berbasis android sebagai media pembelajaran jarak jauh dapat menumbuhkan motivasi belajar siswa kelas VII SMPN 11 Pekalongan.

Karena terbukti bahwa penggunaan aplikasi mobile learning berbasis android sebagai media pembelajaran jarak jauh dapat menumbuhkan motivasi belajar siswa kelas VII SMPN 11 Pekalongan maka guru-guru lain bisa menggunakan aplikasi mobile learning berbasis android untuk melaksanakan pembelajaran jarak jauh dalam jaringan.

\section{Pustaka}

Alwan, M. (2018). Pengembangan multimedia e-book 3D berbasis mobile learning untuk mata pelajaran geografi SMA guna mendukung pembelajaran jarak jauh. At-Tadbir: Jurnal Manajemen Pendidikan Islam,2(1), 26-40. https://doi.org/10.3454/at-tadbir.v1i2.3009

Amirullah, G., \& Hardinata, R. (2017). Pengembangan mobile learning bagi pembelajaran. JKKP (Jurnal Kesejahteraan Keluarga Dan Pendidikan), 4(02), 97-101. https://doi.org/10.21009/JKKP.042.07

Emda, A. (2018). Kedudukan motivasi belajar siswa dalam pembelajaran. Lantanida Journal, 5(2), 172-182. http://dx.doi.org/10.22373/lj.v5i2.2838

Ibrahim, N., \& Ishartiwi, I. (2017). Pengembangan Media Pembelajaran Mobile Learning Berbasis Android Mata Pelajaran Ipa Untuk Siswa Smp. Refleksi Edukatika: Jurnal Ilmiah Kependidikan, 8(1). https://doi.org/10.24176/re.v8i1.1792

Kompri. (2016). Motivasi pembelajaran perspektif guru dan siswa. Bandung: PT Rosda Karya.

Latip, A. (2020). Peran literasi teknologi informasi dan komunikasi pada pembelajaran jarak jauh di masa pandemi Covid-19. EduTeach: Jurnal Edukasi dan Teknologi Pembelajaran, 1(2), 108-116. https://doi.org/10.37859/eduteach.v1i2.1956

Megawanti, P. (2020). Persepsi Peserta Didik Terhadap PJJ pada Masa Pandemi Covid 19. Jurnal Faktor UNINDRA, 7(2), 75-82. http://dx.doi.org/10.30998/fjik.v7i2.6411

Setyadi, D. (2017). Pengembangan mobile learning berbasis android sebagai sarana berlatih mengerjakan soal matematika. Satya Widya,33(2), 87-92. https://doi.org/10.24246/j.sw.2017.v33.i2.p87-92

Uno, H. B. (2016). Teori motivasi dan pengukurannya analisis di bidang pendidikan. Jakarta: PT. Bumi Aksara.

Warsita, B. (2018). Teknologi pembelajaran, landasan dan aplikasinya. Jakarta: Penerbit Reneka Cipta. 